\title{
Serum Blood Urea Nitrogen and Plasma Brain Natriuretic Peptide and Low Diastolic Blood Pressure Predict Cardiovascular Morbidity and Mortality Following Discharge in Acute Decompensated Heart Failure Patients
}

\author{
Chun-Yen Chen, MD; Akemi Yoshida, MD; Masanori Asakura, MD, PhD; \\ Takuya Hasegawa, MD, PhD; Hiroyuki Takahama, MD, PhD; Makoto Amaki, MD, PhD; \\ Akira Funada, MD, PhD; Hiroshi Asanuma, MD, PhD; Hiroyuki Yokoyama, MD, PhD; \\ Jiyoong Kim, MD; Hideaki Kanzaki, MD; Masafumi Kitakaze, MD, PhD
}

\begin{abstract}
Background: Patients with heart failure (HF) have a high risk of cardiovascular (CV) death and re-hospitalization. The purpose of the present study was therefore to investigate predictors of $\mathrm{CV}$ death and re-hospitalization for acute decompensated HF (ADHF).
\end{abstract}

\begin{abstract}
Methods and Results: A total of 225 patients aged 67.2 \pm 15.2 years, including 134 men (59.6\%), who were hospitalized for ADHF between 2008 and 2009, were followed up. After discharge, the relationship between clinical parameters and CV events (ie, CV death or re-hospitalization for HF) was examined. Follow-up was continued until 30 April 2011. The most important predictors of re-hospitalization were serum blood urea nitrogen (BUN; adjusted hazard ratio $[\mathrm{HR}], 1.02 ; 95 \%$ confidence interval [Cl]: 1.00-1.03, $\mathrm{P}=0.01$ ), plasma brain natriuretic peptide (BNP; adjusted $\mathrm{HR}, 1.85 ; 95 \% \mathrm{Cl}: 1.12-3.04, \mathrm{P}=0.02$ ), and diastolic blood pressure (DBP; adjusted $\mathrm{HR}, 0.97 ; 95 \% \mathrm{Cl}: 0.94-1.00$, $\mathrm{P}=0.049$ ). The only predictor of CV mortality was a high BUN (adjusted HR, 1.05; 95\% Cl: 1.01-1.09, $\mathrm{P}=0.01$ ).
\end{abstract}

Conclusions: High serum BUN ( $\geq 22.5 \mathrm{mg} / \mathrm{dl})$, high plasma BNP $(\geq 250 \mathrm{pg} / \mathrm{ml})$, and low DBP $(<60 \mathrm{mmHg}) \mathrm{predict} \mathrm{CV}$ events in patients hospitalized for ADHF. These factors may identify high-risk patients for CV events and provide therapeutic targets for managing HF. (Circ $J$ 2012; 76: 2372-2379)

Key Words: Blood pressure; Blood urea nitrogen; Brain natriuretic peptide; Heart failure

$\mathbf{O}$ ver the past 2 decades, various therapeutic strategies for the treatment of chronic heart failure (CHF) have been developed, and have led to improvement of the survival rate for patients with CHF. Although current interventions can slow the progression of $\mathrm{CHF}$, most patients are eventually hospitalized with acute decompensated HF (ADHF). It has been reported that patients hospitalized for CHF have a high risk of cardiovascular (CV) death and readmission, with a 6-month readmission rate as high as 50\%. ${ }^{1}$ Among 2,445 residents with confirmed ADHF, the 1-year mortality after discharge from hospital was $37.3 \% .^{2}$ The Prospective Trial of Intravenous Milrinone for Exacerbations of Chronic Heart Failure (OPTIME-CHF) and the Evaluation Study of Congestive
Heart Failure and Pulmonary Artery Catheterization Effectiveness (ESCAPE) determined a death rate of 8.9-10.3\% within 60 days of discharge and 19\% within 6 months, respectively.,4 The results of such clinical trials, however, may not be representative of current practice or applicable to general CHF patients because these clinical trials conducted in Europe and/or the USA were based on selected patients enrolled in clinical trials. Interestingly, the Chronic Heart Failure Analysis and Registry in the Tohoku District 2 Study (CHART-2) done in Japan also found that the prevalence of ischemic etiology and risk factors (hypertension (HTN) and diabetes) have increased, and that mortality is the same as in Western studies. ${ }^{5}$

Received January 16, 2012; revised manuscript received May 11, 2012; accepted May 31, 2012; released online July 4, 2012 Time for primary review: 18 days

Department of Cardiovascular Medicine, National Cerebral and Cardiovascular Center, Suita (C.-Y.C., A.Y., M. Asakura, T.H., H.T., M. Amaki, A.F., H.A., H.Y., J.K., H.K., M.K.), Japan; Cardiovascular Division, Department of Internal Medicine, Mackay Memorial Hospital, Taipei (C.-Y.C.); and Mackay Medicine, Nursing and Management College, Taipei (C.-Y.C.), Taiwan

Mailing address: Masafumi Kitakaze, MD, PhD, Department of Cardiovascular Medicine, National Cerebral and Cardiovascular Center, 5-7-1 Fujishirodai, Suita 565-8565, Japan. E-mail: kitakaze@ zf6.so-net.ne.jp

ISSN-1346-9843 doi:10.1253/circj.CJ-12-0040

All rights are reserved to the Japanese Circulation Society. For permissions, please e-mail: cj@j-circ.or.jp 


\section{Editorial p 2329}

To identify the patients at high risk for re-hospitalization or $\mathrm{CV}$ death, stratification of risk for mortality or morbidity among all of the available clinical parameters is necessary in a clinical cohort study of CHF patients, but such trials have not been performed. Therefore, it is necessary to identify useful markers to help $\mathrm{CV}$ physicians identify HF patients that have a high long-term risk of events at the time of discharge.

To identify such useful predictors, we conducted an analysis of clinical data in a hospital-based registry of ADHF patients to identify factors related to either long-term $\mathrm{CV}$ death or re-hospitalization for HF in CHF patients who mainly suffered from dilated cardiomyopathy (DCM) and who were admitted with ADHF.

\section{Methods}

\section{Subjects}

This study was conducted in accordance with the Declaration of Helsinki and received approval from the ethics committee of the National Cerebral and Cardiovascular Center. Consecutive patients who had a discharge diagnosis of ADHF were eligible for entry into the hospital registry. Data were analyzed for 251 consecutive patients admitted to the National Cerebral and Cardiovascular Center (Suita, Japan) between December 2008 and December 2009 because of ADHF (New York Heart Association class III-IV). Patients who died in hospital or who did not have complete clinical data at discharge were excluded. If HF was not the reason for hospitalization, the patients were also excluded. Patients with CHF caused by chronic kidney disease or acute renal failure and with hemodialysis were excluded. We discontinued follow-up in April 2011. The demographic profile, medical history, medications at discharge, laboratory test results, echocardiography findings, and clinical outcomes were obtained from the hospital registry. We recorded blood pressure (BP) 3 times and averaged them on the day of discharge. A fasting blood sample was obtained before discharge after an overnight fast (10-12h) for measurement of plasma brain natriuretic peptide (BNP) and serum blood urea nitrogen $(\mathrm{BUN})$, creatinine $(\mathrm{Cr})$, aspartate aminotransferase, alanine aminotransferase, total bilirubin, uric acid, sodium, potassium, and fasting blood glucose (FBG). Estimated glomerular filtration rate (eGFR) was calculated as: $194 \times \mathrm{age}^{-0.287} \times$ serum $\mathrm{Cr}^{-1.094}(\times 0.739$ if female). HTN was defined as present in patients with (1) a history of hypertension or (2) a systolic BP $(\mathrm{SBP}) \geq 140 \mathrm{mmHg}$ or diastolic BP (DBP) $\geq 90 \mathrm{mmHg}$. Patients with a history of diabetes mellitus (DM) or an FBG $\geq 126 \mathrm{mg} / \mathrm{dl}$ were defined as having DM. Hyperlipidemia was defined as total cholesterol $\geq 200 \mathrm{mg} / \mathrm{dl}$ or triglycerides $\geq 150 \mathrm{mg} / \mathrm{dl}$.

\section{Endpoints}

The primary endpoint was either $\mathrm{CV}$ death or re-hospitalization for HF, and these endpoints were analyzed on a time-to-event basis. All outcomes were decided by 3 cardiologists. Re-hospitalization was defined as a new admission for HF after discharge from hospital following admission for ADHF. CV death was defined as death from CV disease. If re-hospitalization or death did not occur, the date of censoring was the date of final follow-up. Follow-up was continued until 30 April 2011.

\section{Statistical Analysis}

Results are expressed as the mean $\pm \mathrm{SD}$ or as percentages.
Students' t-test was used to compare differences between groups for continuous variables and the chi-square test was used for categorical data. If data had a skewed distribution, including BNP, logarithmic transformation was done before statistical analysis. Cox proportional hazards regression analysis was used to evaluate the association of variables with re-hospitalization or CV mortality. Re-hospitalization due to HF and CV mortality event-free curves were drawn using the Kaplan-Meier method and were compared using the log-rank test. Analysis was performed with SPSS version 12.0 (SPSS, Chicago, IL, USA) and STATA version 11.0 (College Station, TX, USA). P<0.05 was considered statistically significant.

\section{Results}

Of the 251 patients enrolled, 21 were excluded due to incomplete data and 5 were excluded because of death in hospital, leaving 225 patients for analysis. Table 1 lists the baseline characteristics of these patients. Clinically relevant features of the re-hospitalized group included a high prevalence of DM, high BUN, low serum sodium, low eGFR, high percentage of use of diuretics (except spironolactone), and low DBP. The difference in plasma BNP according to re-hospitalization was borderline significant. Patients who succumbed to CV death were older, had low DBP, high plasma BNP and BUN, and low serum sodium. There was no difference in prevalence of etiologies according to re-hospitalization or CV death. There was no difference in the prevalence of aortic regurgitation according to re-hospitalization $(6.3 \%$ vs. $8.0 \% \mathrm{P}=0.80)$. The $\mathrm{BUN} / \mathrm{Cr}$ ratio and the prevalence of $\mathrm{BUN} / \mathrm{Cr}>10$ did not differ according to re-hospitalization. The patients who succumbed to $\mathrm{CV}$ death had a higher BUN/Cr. The prevalence of BUN/Cr $>10$ did not differ according to $\mathrm{CV}$ death. The dose of furosemide was higher in patients with re-hospitalization and CV death.

To obtain the cut-offs for these parameters, receiver operating characteristic (ROC) curve analysis was used, and $22.5 \mathrm{mg} / \mathrm{dl}$, $2.4 \mathrm{pg} / \mathrm{ml}(250 \mathrm{pg} / \mathrm{ml}), 60 \mathrm{mmHg}$ and $137.5 \mathrm{mmol} / \mathrm{dl}$ appeared to be optimal cut-offs to create dichotomous variables for valves of BUN, log BNP (plasma BNP), DBP and serum sodium, respectively. The selection of cut-offs was challenging due to the large decreases in specificity as sensitivity increased. Although the furosemide dose in patients with BUN $\geq 22.5 \mathrm{mg} / \mathrm{dl}$ was higher than in those with BUN $<22.5 \mathrm{mg} / \mathrm{dl}(45.8 \pm 35.9 \mathrm{mg}$ vs. $30.3 \pm 19.9 \mathrm{mg}, \mathrm{P}=0.001$ ), there were no differences in the doses of spironolactone, torasemide and trichlormethiazide (spironolactone: $28.9 \pm 12.1 \mathrm{mg}$ vs. $28.3 \pm 11.6 \mathrm{mg}, \mathrm{P}=0.77$; torasemide: $8.9 \pm 8.6 \mathrm{mg}$ vs. $5.1 \pm 2.0 \mathrm{mg}, \mathrm{P}=0.16$; trichlormethiazide: $1.6 \pm 0.7 \mathrm{mg}$ vs. $1.6 \pm 0.5 \mathrm{mg}, \mathrm{P}=0.79$ ).

The Cox proportional hazards model showed that BUN, DBP, and plasma BNP were independent predictors of re-hospitalization (Table 2). Hazard ratios (HR) for the endpoint of rehospitalization indicated that BUN, DBP, and BNP were significantly associated with readmission for $\mathrm{HF}$ (unadjusted $\mathrm{HR}$, 1.02 ; $95 \%$ confidence interval $[\mathrm{CI}]: 1.01-1.03$; unadjusted HR, 0.96; 95\% CI: 0.94-0.98; unadjusted HR, 1.62; 95\% CI: 1.082.43 , respectively). Also, these 3 variables remained significant (adjusted HR, 1.02; 95\% CI: 1.00-1.03; adjusted HR, 1.85; 95\% CI: 1.12-3.04; and adjusted HR, 0.97; 95\% CI: 0.94-1.00, respectively) even after adjusting for age, gender, SBP, serum $\mathrm{Cr}$, serum sodium, DM, HTN, hyperlipidemia, and use of $\beta$ blockers, angiotensin-converting enzyme inhibitors (ACEI), angiotensin receptor blockers (ARB), spironolactone, and other diuretics. When BUN, BNP, and DBP were incorporated as continuous variables, we found that there was a $2 \%$ increase in the risk of re-hospitalization for every $1-\mathrm{mg} / \mathrm{dl}$ increase in 


\begin{tabular}{|c|c|c|c|c|c|c|}
\hline \multirow[b]{3}{*}{ Demographics } & \multicolumn{3}{|c|}{ Re-hospitalization ( $n=225)$} & \multicolumn{3}{|c|}{ CV mortality $(n=225)$} \\
\hline & Yes $(n=112)$ & No $(n=113)$ & $P$ value & Yes $(n=23)$ & No $(n=202)$ & $P$ value \\
\hline & & & & & & \\
\hline Age (years) & $68.3 \pm 14.7$ & $66.2 \pm 15.6$ & 0.30 & $73.5 \pm 13.9$ & $66.5 \pm 15.2$ & 0.04 \\
\hline Male & $70(62.5)$ & $64(56.6)$ & 0.42 & $14(60.9)$ & $120(59.4)$ & 1.00 \\
\hline \multicolumn{7}{|l|}{ Medical history } \\
\hline HTN & $53(47.3)$ & $64(56.6)$ & 0.18 & $13(56.5)$ & $104(51.5)$ & 0.67 \\
\hline DM & $43(38.4)$ & $27(28.9)$ & 0.02 & $9(39.1)$ & $61(29.4)$ & 0.48 \\
\hline Hyperlipidemia & 35 (31.3) & $35(31.0)$ & 1.00 & 9 (39.1) & $61(30.2)$ & 0.48 \\
\hline \multicolumn{7}{|l|}{ Clinical characteristics } \\
\hline $\mathrm{SBP}(\mathrm{mmHg})$ & $110.1 \pm 16.2$ & $114.2 \pm 16.1$ & 0.07 & $110.4 \pm 17.8$ & $112.4 \pm 16.1$ & 0.58 \\
\hline $\mathrm{DBP}(\mathrm{mmHg})$ & $58.8 \pm 8.9$ & $63.1 \pm 10.0$ & 0.001 & $56.9 \pm 7.6$ & $61.5 \pm 9.8$ & 0.03 \\
\hline HR (beats/min) & $75.0 \pm 68.9$ & $68.6 \pm 11.7$ & 0.34 & $71.3 \pm 13.0$ & $71.8 \pm 51.5$ & 0.97 \\
\hline LVDd (mm) & $59.4 \pm 14.0$ & $58.0 \pm 11.3$ & 0.45 & $59.3 \pm 13.8$ & $58.6 \pm 12.6$ & 0.82 \\
\hline LVDs (mm) & $47.9 \pm 16.0$ & $46.4071 \pm 14.0$ & 0.45 & $49.7 \pm 15.7$ & $46.9 \pm 14.9$ & 0.41 \\
\hline FS (\%) & $21.1 \pm 11.9$ & $21.4 \pm 13.4$ & 0.84 & $18.1 \pm 9.8$ & $21.6 \pm 12.9$ & 0.21 \\
\hline \multicolumn{7}{|l|}{ Laboratory values } \\
\hline Log BNP (pg/ml) & $2.4 \pm 0.5$ & $2.3 \pm 0.5$ & 0.06 & $2.5 \pm 0.5$ & $2.3 \pm 0.5$ & 0.05 \\
\hline Uric acid (mg/dl) & $7.5 \pm 2.1$ & $7.1 \pm 2.1$ & 0.19 & $8.2 \pm 2.0$ & $7.2 \pm 2.1$ & 0.04 \\
\hline Total bilirubin (mg/dl) & $0.7 \pm 0.4$ & $0.7 \pm 0.3$ & 0.44 & $0.6 \pm 0.3$ & $0.7 \pm 0.4$ & 0.53 \\
\hline AST (U/L) & $28.9 \pm 12.7$ & $25.9 \pm 12.6$ & 0.08 & $27.9 \pm 12.3$ & $27.4 \pm 12.8$ & 0.84 \\
\hline ALT (U/L) & $23.9 \pm 17.8$ & $23.5 \pm 23.1$ & 0.87 & $18.9 \pm 13.3$ & $24.3 \pm 21.2$ & 0.24 \\
\hline BUN (mg/dl) & $31.3 \pm 21.5$ & $24.0 \pm 13.0$ & 0.002 & $42.4 \pm 34.3$ & $26.0 \pm 14.4$ & 0.03 \\
\hline $\mathrm{BUN} / \mathrm{Cr}$ & $24.8 \pm 8.3$ & $23.9 \pm 13.8$ & 0.57 & $29.1 \pm 8.0$ & $23.8 \pm 11.6$ & 0.04 \\
\hline $\mathrm{BUN} / \mathrm{Cr}>10$ & $110(98.2)$ & $109(96.5)$ & 0.68 & $23(100)$ & $196(97.0)$ & 1.00 \\
\hline Serum Cr (mg/dl) & $1.3 \pm 0.7$ & $1.2 \pm 1.4$ & 0.76 & $1.4 \pm 1.0$ & $1.2 \pm 1.1$ & 0.35 \\
\hline eGFR $\left(\mathrm{ml} \cdot \mathrm{min}^{-1} \cdot 1.73 \mathrm{~m}^{-2}\right)$ & $50.0 \pm 21.8$ & $61.0 \pm 44.6$ & 0.02 & $47.9 \pm 26.0$ & $56.4 \pm 36.4$ & 0.28 \\
\hline Serum sodium (mmol/L) & $136.9 \pm 4.2$ & $137.9 \pm 3.7$ & 0.05 & $135.7 \pm 4.2$ & $137.6 \pm 3.9$ & 0.03 \\
\hline Serum potassium (mmol/L) & $4.3 \pm 0.5$ & $4.4 \pm 0.5$ & 0.25 & $4.3 \pm 0.5$ & $4.3 \pm 0.5$ & 0.41 \\
\hline \multicolumn{7}{|l|}{ Etiology of HF } \\
\hline DCM & $85(75.9)$ & 88 (77.9) & 0.15 & $18(78.3)$ & $155(76.7)$ & 0.38 \\
\hline ICM & $3(2.7)$ & $0(0)$ & & $1(4.3)$ & $2(1.0)$ & \\
\hline VHD & $18(16.1)$ & $19(16.8)$ & & $4(17.3)$ & $33(16.3)$ & \\
\hline $\mathrm{HCM}$ & $6(5.4)$ & $12(10.6)$ & & $0(0)$ & $18(8.9)$ & \\
\hline Others & $7(6.3)$ & $3(2.7)$ & & $1(4.3)$ & $9(4.5)$ & \\
\hline \multicolumn{7}{|l|}{ Medication at discharge } \\
\hline$\beta$-blocker & $72(64.3)$ & $69(61.1)$ & 0.68 & $13(56.5)$ & $128(63.4)$ & 0.51 \\
\hline ACEI & $47(42.0)$ & $46(40.7)$ & 0.89 & $10(43.5)$ & $83(41.1)$ & 0.83 \\
\hline ARB & $26(23.2)$ & $23(20.4)$ & 0.63 & $3(13.0)$ & $46(22.8)$ & 0.42 \\
\hline Spironolactone & $65(58.0)$ & $57(50.4)$ & 0.29 & $12(52.2)$ & $110(54.5)$ & 0.83 \\
\hline Spironolactone (mg) & $27.9 \pm 11.4$ & $29.5 \pm 12.4$ & 0.44 & $28.5 \pm 12.5$ & $28.6 \pm 11.8$ & 0.98 \\
\hline Diuretics except spironolactone & $94(83.9)$ & $81(71.7)$ & 0.04 & $20(87.0)$ & $155(76.7)$ & 0.30 \\
\hline Furosemide (mg) & $44.6 \pm 35.9$ & $32.9 \pm 21.7$ & 0.006 & $63.5 \pm 52.2$ & $35.2 \pm 24.7$ & 0.03 \\
\hline Torasemide (mg) & $8.4 \pm 8.2$ & $5.3 \pm 2.6$ & 0.29 & $6.0 \pm 5.3$ & $7.6 \pm 7.3$ & 0.72 \\
\hline Trichlormethiazide (mg) & $1.6 \pm 0.8$ & $1.6 \pm 0.5$ & 0.99 & $1.0 \pm 0.0$ & $1.7 \pm 0.7$ & 0.04 \\
\hline
\end{tabular}

Data given as mean $\pm \mathrm{SD}$ or $\mathrm{n}(\%)$.

ACEI, angiotensin-converting enzyme inhibitor; ADHF, acute decompensated heart failure; ALT, alanine aminotransferase; ARB, angiotensin receptor blocker; AST, aspartate aminotransferase; BNP, brain natriuretic peptide; BUN, blood urea nitrogen; $\mathrm{Cr}$, creatinine; CV, cardiovascular; DBP, diastolic blood pressure; DCM, dilated cardiomyopathy; DM, diabetes mellitus; eGFR, estimated glomerular filtration rate (194×age $-0.287 \times$ serum $\mathrm{Cr}^{-1.094}(\times 0.739$ if female)); FS, fractional shortening; HCM, hypertrophic cardiomyopathy; HF, heart failure; HR, heart rate; HTN, hypertension; ICM, ischemic cardiomyopathy; LVDd, left ventricular diastolic diameter; LVDs, left ventricular systolic diameter; SBP, systolic blood pressure; VHD, valvular heart disease.

BUN, as well as an $8.5 \%$ increase in risk for every $1-\mathrm{pg} / \mathrm{ml}$ increase in BNP. There was also a 3\% decrease in the risk of re-hospitalization for every 1-mmHg increase of DBP. We found that adjusted odds ratio (OR) of BUN $\geq 22.5 \mathrm{mg} / \mathrm{dl}$ vs. $<22.5 \mathrm{mg} / \mathrm{dl}, \log (\mathrm{BNP}) \geq 2.4 \mathrm{pg} / \mathrm{ml}$ vs. $<2.4 \mathrm{pg} / \mathrm{ml}$ (BNP $\geq 250 \mathrm{pg} / \mathrm{ml} \mathrm{vs} .<250 \mathrm{pg} / \mathrm{ml}$ ) and DBP $\geq 60 \mathrm{mmHg}$ vs. $<60 \mathrm{mmHg}$ were 1.58 (95\% CI: 1.01-2.49, P=0.047), 1.57 (95\% CI: $1.05-$ 2.43, $\mathrm{P}=0.03$ ) and 0.57 (95\% CI: 0.36-0.91, $\mathrm{P}=0.02$ ) after adjustment for the aforementioned parameters. In contrast, only BUN was associated with a significant increase of $\mathrm{CV}$ death (unadjusted HR, 1.03; 95\% CI: 1.02-1.04), and this association remained significant (adjusted HR, 1.05; 95\% CI: 1.01- 


\begin{tabular}{|c|c|c|c|c|}
\hline \multirow[b]{3}{*}{ Re-hospitalization cohort } & \multicolumn{2}{|c|}{ Univariate model } & \multicolumn{2}{|c|}{ Multivariate model } \\
\hline & Hazard ratio & $P$ value & Hazard ratio & $P$ value \\
\hline & & & & \\
\hline Age (per year) & $1.01(1.00-1.03)$ & 0.10 & $1.01(1.00-1.03)$ & 0.13 \\
\hline Gender (male vs. female) & $1.16(0.79-1.70)$ & 0.46 & $1.19(0.77-1.84)$ & 0.44 \\
\hline SBP (per mmHg) & $0.99(0.97-1.00)$ & 0.03 & $1.01(0.99-1.02)$ & 0.58 \\
\hline DBP (per mmHg) & $0.96(0.94-0.98)$ & $<0.001$ & $0.97(0.94-1.00)$ & 0.049 \\
\hline LogBNP (per pg/ml) & $1.62(1.08-2.43)$ & 0.02 & $1.85(1.12-3.04)$ & 0.02 \\
\hline BUN (per mg/dl) & $1.02(1.01-1.03)$ & $<0.001$ & $1.02(1.00-1.03)$ & 0.01 \\
\hline Serum Cr (per mg/dl) & $1.00(0.88-1.14)$ & 0.99 & $0.84(0.61-1.15)$ & 0.28 \\
\hline Serum sodium (per mmol/L) & $0.94(0.90-0.99)$ & 0.009 & $0.97(0.92-1.03)$ & 0.31 \\
\hline DM & $1.16(0.94-1.44)$ & 0.16 & $1.07(0.84-1.37)$ & 0.60 \\
\hline HTN & $0.80(0.55-1.16)$ & 0.24 & $0.72(0.45-1.17)$ & 0.19 \\
\hline Hyperlipidemia & $1.04(0.70-1.55)$ & 0.85 & $1.03(0.67-1.58)$ & 0.91 \\
\hline$\beta$-blocker & $1.00(0.68-1.47)$ & 1.00 & $1.09(0.68-1.75)$ & 0.73 \\
\hline ACEI & $1.08(0.74-1.58)$ & 0.68 & $1.32(0.84-2.09)$ & 0.23 \\
\hline ARB & $0.99(0.64-1.54)$ & 0.97 & $1.38(0.81-2.35)$ & 0.24 \\
\hline Spironolactone & $1.26(0.86-1.83)$ & 0.23 & $1.11(0.73-1.69)$ & 0.62 \\
\hline Diuretics use except spironolactone & $1.72(1.04-2.84)$ & 0.04 & $1.47(0.85-2.52)$ & 0.17 \\
\hline \multicolumn{5}{|l|}{ Cardiovascular mortality cohort } \\
\hline Age (per year) & $1.04(1.01-1.08)$ & 0.03 & $1.02(0.98-1.07)$ & 0.31 \\
\hline Gender (male vs. female) & $1.00(0.43-2.30)$ & 0.99 & $1.20(0.47-3.06)$ & 0.70 \\
\hline SBP (per mmHg) & $0.99(0.97-1.02)$ & 0.54 & $1.01(0.98-1.05)$ & 0.47 \\
\hline DBP (per mmHg) & $0.94(0.89-0.99)$ & 0.02 & $0.94(0.88-1.01)$ & 0.10 \\
\hline LogBNP (per pg/ml) & $2.58(1.08-6.18)$ & 0.03 & $2.34(0.89-6.00)$ & 0.09 \\
\hline BUN (per mg/dl) & $1.03(1.02-1.04)$ & $<0.001$ & $1.05(1.01-1.09)$ & 0.01 \\
\hline Serum $\mathrm{Cr}$ (per mg/dl) & $1.10(0.88-1.37)$ & 0.42 & $0.38(0.10-1.50)$ & 0.17 \\
\hline Serum sodium (per mmol/L) & $0.91(0.83-0.99)$ & 0.03 & $0.97(0.86-1.09)$ & 0.59 \\
\hline DM & $1.48(0.64-3.42)$ & 0.36 & $1.15(0.42-3.15)$ & 0.79 \\
\hline HTN & $1.23(0.54-2.80)$ & 0.63 & $0.83(0.29-2.41)$ & 0.74 \\
\hline Hyperlipidemia & $1.38(0.60-3.18)$ & 0.46 & $1.17(0.40-3.39)$ & 0.77 \\
\hline$\beta$-blocker & $0.74(0.32-1.68)$ & 0.46 & $0.90(0.31-2.59)$ & 0.85 \\
\hline ACEI & $1.08(0.47-2.47)$ & 0.85 & $1.50(0.57-3.95)$ & 0.42 \\
\hline ARB & $0.52(0.16-1.76)$ & 0.30 & $0.81(0.21-3.23)$ & 0.77 \\
\hline Spironolactone & $0.91(0.40-2.06)$ & 0.82 & $0.67(0.25-1.82)$ & 0.43 \\
\hline Diuretics use except spironolactone & $1.96(0.58-6.58)$ & 0.28 & $1.66(0.46-5.95)$ & 0.44 \\
\hline
\end{tabular}

Abbreviations as in Table 1.

1.09) after adjustment for the aforementioned parameters. When BUN was incorporated as a continuous variable, we found that it was the strongest predictor of $\mathrm{CV}$ mortality and that there was a $5 \%$ increase in the risk of CV death for every 1-mg/dl increase in BUN. In contrast, serum $\mathrm{Cr}$ was not an independent predictor of either re-hospitalization or $\mathrm{CV}$ death. When the $\mathrm{Cr}$ was replaced by eGFR in the regression model, the OR of eGFR was 1.00 (95\% CI: 0.99-1.00, $\mathrm{P}=0.26$ ). eGFR was not found to be an independent predictor of re-hospitalization in the present study.

Given that BUN was found to be a shared and strong predictor of both $\mathrm{CV}$ death and re-hospitalization for HF, we stratified the patients according to serum BUN level to examine whether the predictive value of BUN overcame the predictive value of plasma BNP or DBP. We divided the patients according to the BUN cut-off of $22.5 \mathrm{mg} / \mathrm{dl}$, thus obtaining low BUN $(<22.5 \mathrm{mg} / \mathrm{dl})$ and high BUN $(\geq 22.5 \mathrm{mg} / \mathrm{dl})$ subgroups. We also divided the patients into 2 groups according to $\log (\mathrm{BNP})=$ $2.4 \mathrm{pg} / \mathrm{ml}$ (BNP, 250 pg/ml) to obtain a low BNP subgroup $(<250 \mathrm{pg} / \mathrm{ml})$ and a high BNP subgroup $(\geq 250 \mathrm{pg} / \mathrm{ml})$. Further- more, we divided the patients into 2 groups at the cut-off DBP of $60 \mathrm{mmHg}$ to obtain a low DBP subgroup $(<60 \mathrm{mmHg})$ and a high DBP subgroup ( $\geq 60 \mathrm{mmHg}$ ). Kaplan-Meier curves for re-hospitalization were plotted for groups with BUN above or below the mean and log BNP above or below the mean (Figure 1). The low BUN + low BNP subgroup had a significantly lower re-hospitalization rate compared with the high BUN+high BNP subgroup, the high BUN+low BNP subgroup, and the low BUN + high BNP subgroup (log-rank test, $\mathrm{P}=0.001$, 0.001 , and 0.001 , respectively). Kaplan-Meier curves for rehospitalization were also plotted for the groups with BUN above or below $22.5 \mathrm{mg} / \mathrm{dl}$ and DBP above or below $60 \mathrm{mmHg}$ (Figure 2). As a result, the low BUN + high DBP subgroup showed a significant decrease of re-hospitalization compared with the low BUN + low DBP subgroup and the high BUN + low DBP subgroup (log-rank test, $\mathrm{P}=0.04$ and $<0.001$, respectively).

Furthermore, Kaplan-Meier curves for re-hospitalization were plotted for groups with BNP above or below $250 \mathrm{pg} / \mathrm{ml}$ and DBP above or below $60 \mathrm{mmHg}$ in the high BUN subgroup (Figure 3A) and in the low BUN subgroup (Figure 3B). In the high BUN 


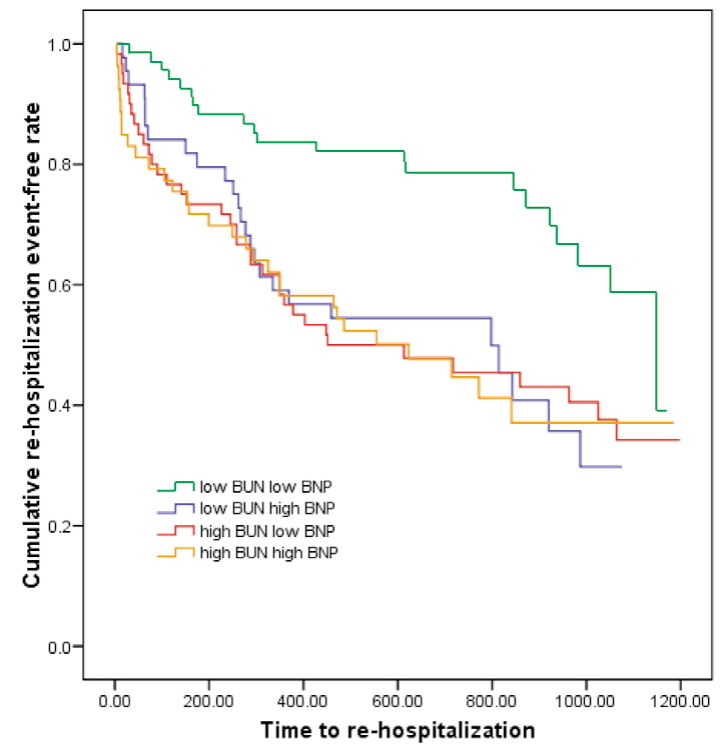

Figure 1. Kaplan-Meier plots for re-hospitalization event-free curves according to different combinations of blood urea nitrogen (BUN) and brain natriuretic peptide (BNP) levels. All participants were divided into 2 groups according to cut-offs for BUN $(22.5 \mathrm{mg} / \mathrm{dl})$ and BNP $(250 \mathrm{pg} / \mathrm{ml})$. Cumulative rehospitalization event-free rates in the low BUN + low BNP subgroup $(n=68)$, low $B U N+$ high BNP subgroup $(n=44)$, high BUN + low BNP subgroup $(n=60)$, and high BUN + high BNP subgroup $(n=53$ ) were $39.3 \%, 29.8 \%, 34.2 \%$ and $37.1 \%$, respectively (log-rank test, $\mathrm{P}=0.002$ ).

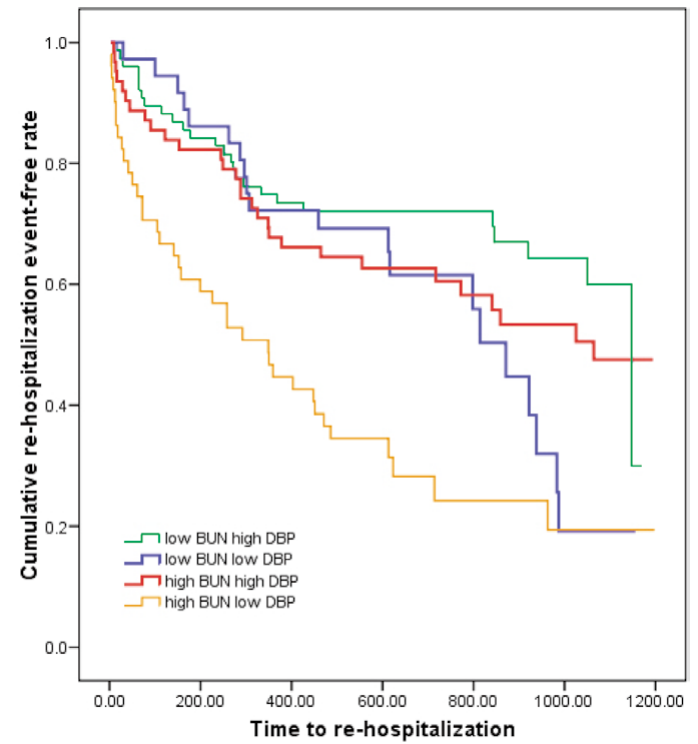

Figure 2. Kaplan-Meier plots for re-hospitalization event-free curves according to different combinations of blood urea nitrogen (BUN) and diastolic blood pressure (DBP) levels. All participants were divided into 2 groups according to mean BUN $(22.5 \mathrm{mg} / \mathrm{dl})$ and DBP $(60 \mathrm{mmHg})$. Cumulative re-hospitalization event-free rates in the low BUN + low DBP subgroup $(n=36)$, low BUN + high DBP subgroup $(n=76)$, high $B U N+$ low DBP subgroup $(n=51)$, and high BUN + high DBP subgroup $(\mathrm{n}=62)$ were $19.2 \%, 30.0 \%, 19.4 \%$ and $47.6 \%$, respectively (log-rank test, $\mathrm{P}<0.001$ ).
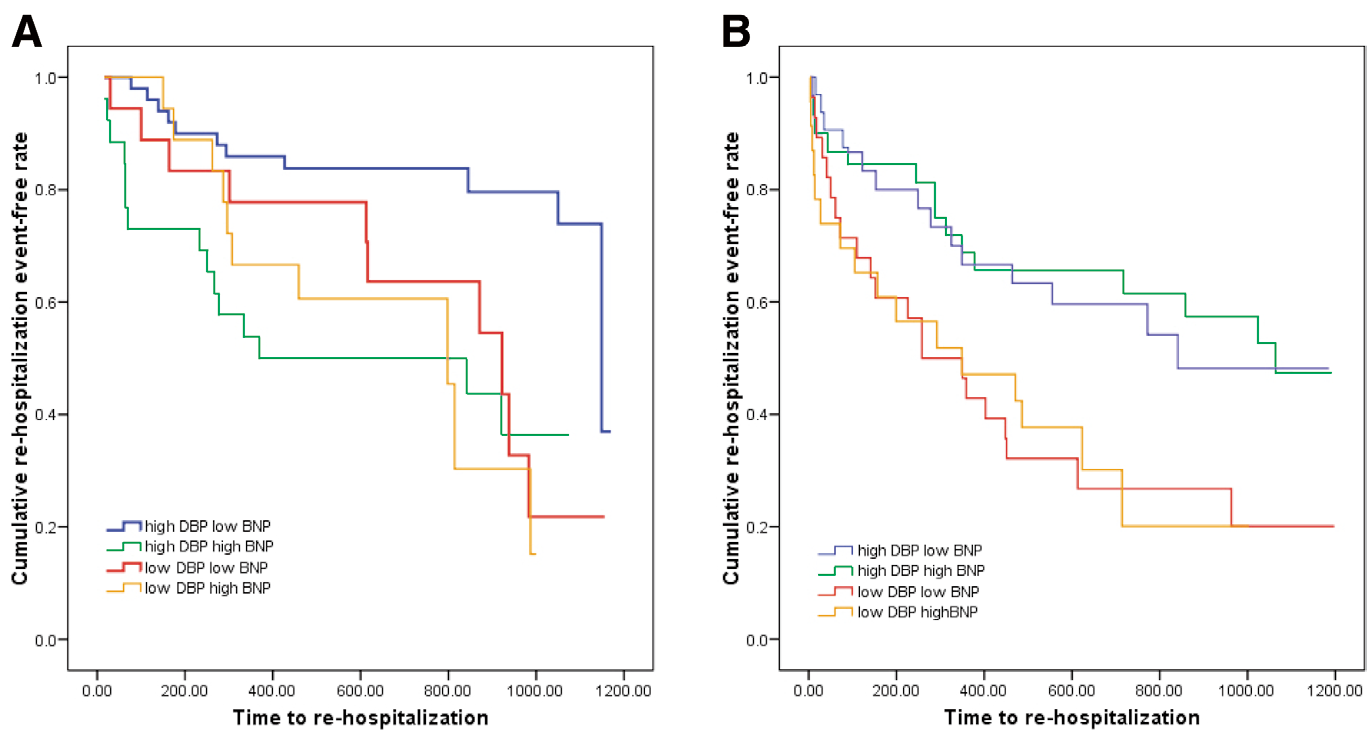

Figure 3. (A) Kaplan-Meier plots for re-hospitalization event-free curves according to different combinations of brain natriuretic peptide (BNP) and diastolic blood pressure (DBP) levels in the low blood urea nitrogen (BUN) subgroup $(<22.5 \mathrm{mg} / \mathrm{dl})$. All participants were divided into 2 groups according to the cut-offs for BNP $(250 \mathrm{pg} / \mathrm{ml})$ and DBP $(60 \mathrm{mmHg})$. Cumulative re-hospitalization event-free rates in the low BNP + low DBP subgroup $(n=18)$, low BNP + high DBP subgroup $(n=50)$, high BNP + low DBP subgroup $(n=18)$, and high BNP + high DBP subgroup $(n=26)$ were $21.8 \%, 37.0 \%, 15.2 \%$ and $36.5 \%$, respectively (log-rank test, $\mathrm{P}=0.001$ ). (B) Kaplan-Meier plots for re-hospitalization event-free curves grouped according to different combinations of BNP and DBP levels in the high BUN subgroup ( $\geq 27.9 \mathrm{mg} / \mathrm{dl})$. All participants were divided into 2 groups according to the mean of BNP $(2.33 \mathrm{pg} / \mathrm{ml})$ and DBP $(61 \mathrm{mmHg})$. Cumulative re-hospitalization event-free rates in the low BNP + low DBP subgroup $(n=28)$, low BNP + high DBP subgroup $(n=32)$, high BNP + low DBP subgroup $(n=23)$, and high BNP + high DBP subgroup $(n=30)$ were $20.1 \%$, $47.4 \%, 20.1 \%$ and $48.2 \%$, respectively (log-rank test, $P=0.005$ ). 
$\mathbf{A}_{8}$

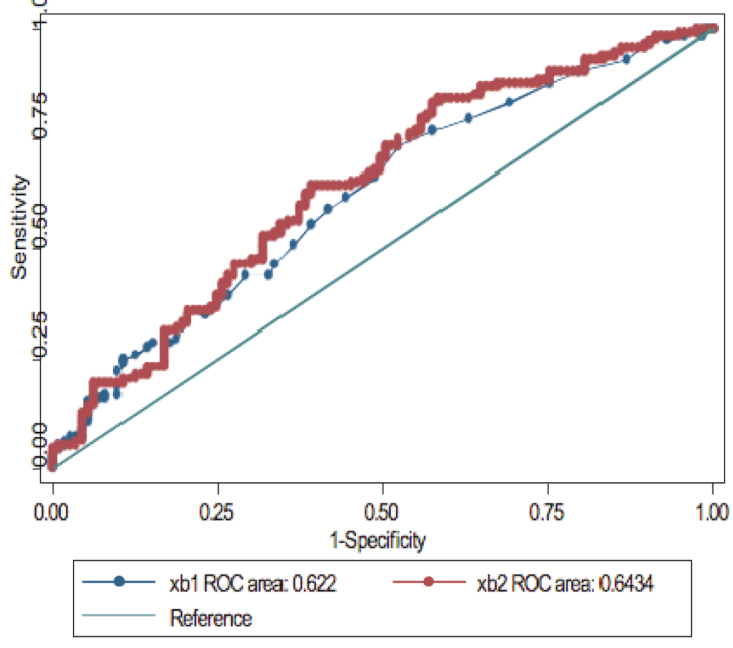

B

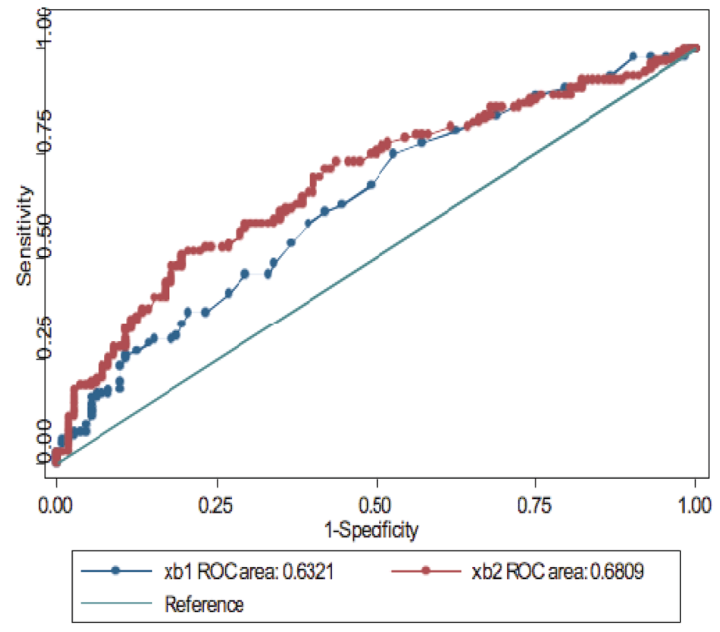

Figure 4. Receiver operating characteristic $(R O C)$ curve for blood urea nitrogen (BUN), brain natriuretic peptide (BNP) and diastolic blood pressure (DBP) in the identification of re-hospitalization with heart failure. The composite of (A) BNP or (B) DBP was not shown to add value significantly beyond BUN alone in identifying re-hospitalization.

subgroup, the low BNP+high DBP subgroup showed a significant decrease of re-hospitalization compared with the low $\mathrm{BNP}+$ low DBP subgroup and the high BNP+low DBP subgroup (log-rank test, $\mathrm{P}=0.006$ and $<0.001$, respectively). In the low BUN subgroup, the low BNP+high DBP subgroup showed a significant decrease of re-hospitalization compared with the high BNP+high DBP subgroup and the low BNP+low DBP subgroup, and the high BNP+low DBP subgroup (log-rank test, $\mathrm{P}<0.001$ and 0.009 and 0.002 , respectively).

The ROC curve data showed that BNP superimposed on the existing BUN level expanded the model from 0.622 to 0.6434 $(\mathrm{P}=0.38)$ and DBP superimposed on the existing BUN level expanded the model from 0.6321 to 0.6809 ( $\mathrm{P}=0.12$; Figure 4).

\section{Discussion}

This study has shown that high serum BUN, high plasma BNP, and low DBP are all associated with re-hospitalization for HF, while high BUN was the only predictor of $\mathrm{CV}$ death in patients with ADHF. These 3 clinical parameters may be useful for predicting the outcome for patients with HF, and as markers of the response to treatment. Because high BUN blunted the predictive value of plasma BNP and DBP, there was a hierarchy of predictive power for these 3 parameters and BUN was tightly associated with future $\mathrm{CV}$ events in patients admitted for ADHF. In fact, high BUN was associated with an increased rate of re-hospitalization for $\mathrm{HF}$ irrespective of either $\mathrm{BNP}$ or DBP.

In the present study, the majority of enrolled patients had DCM, suggesting that the present conclusion may be more applicable to patients with DCM. Indeed, the prevalence (76.9\%) of DCM in the present study was greater than in the Japanese Cardiac Registry of Heart Failure in Cardiology (JCARECARD) study $(24.0 \%),{ }^{6}$ suggesting that the severity of HF in the present study was higher than average. Therefore, the present results may be more applicable to patients with DCM. Indeed, the Beta-blocker Evaluation of Survival Trial (BEST) study showed that low survival rate is associated with elevated BUN in patients with compensated chronic HF caused by primary or secondary DCM and a left ventricular ejection fraction (LVEF) $\leq 35 \%,{ }^{7}$ which is consistent with the present study. In contrast, according to the Acute Decompensated Heart Failure National Registry (ADHERE), the best single predictor of in-hospital death was high BUN ( $\geq 43 \mathrm{mg} / \mathrm{dl}$ ) among 39 variables tested. ${ }^{8}$ These results are in agreement with the present findings. An increase of BUN has been found to be a better predictor of mortality and re-hospitalization than the serum $\mathrm{Cr}$ level or the GFR in recent studies, ${ }^{9,10}$ and these findings were also consistent with the present ones. We assessed CV mortality, however, while other studies investigated all-cause mortality, ${ }^{7,9,10}$ so the present data suggest that abnormal renal function may cause deterioration of cardiac function that results in $\mathrm{CV}$ death. In patients with HF, low cardiac output decreases renal blood flow and GFR, leading to an increase of urea and thus BUN, so a low cardiac output is linked to high BUN. BUN may also be affected by intestinal function, nutritional status such as protein intake or systemic catabolism, and neurohumoral factors. For example, arginine vasopressin influences reabsorption of urea in the collecting tubule, ${ }^{11}$ and norepinephrine has been reported to be increased in patients with BUN $>21.0 \mathrm{mg} / \mathrm{dl} .^{12}$ Therefore, the pathophysiological role of BUN may be different from that of serum Cr or GFR, and BUN may be a specific and independent biomarker of re-hospitalization and $\mathrm{CV}$ death in patients with ADHF because higher BUN is linked with $\mathrm{CV}$ death in HF patients. The BUN concentration is not only influenced by tubular re-absorption of urea in the kidneys, but also by protein intake and systemic catabolism, so high BUN may be related to multiple aspects of the pathophysiology of CHF.

The present study has indicated that high BNP and low DBP are also associated with a higher risk of re-hospitalization. Cheng et al found that BNP $<430 \mathrm{pg} / \mathrm{ml}$ at the time of discharge was a strong negative predictor of re-hospitalization, ${ }^{13}$ and the Outcomes of a Prospective Trial of Intravenous Milrinone for 
Exacerbations of Chronic Heart Failure (OPTIMIZE-HF) study showed that the BNP level at discharge was the best predictor of 1-year mortality and/or re-hospitalization among older patients ( $\geq 65$ years) hospitalized with HF. ${ }^{14}$ Increase in BNP is useful for predicting cardiac events in stable outpatients with non-ischemic chronic HF. ${ }^{15}$ Logeart et al found that when HF patients have a $70 \%$ prevalence of systolic dysfunction of LVEF $(<45 \%)$, high BNP at pre-discharge assessment is a strong, independent marker of death or re-admission after decompensated congestive HF, ${ }^{16}$ which is also consonant with the present result that the prevalence of DCM with systolic dysfunction was $76.9 \%$. In addition, Javaheri et al reported that low DBP was associated with worse survival in patients with HF and a decreased ejection fraction. ${ }^{17}$ Moreover, the Framingham study showed that DBP was negatively correlated with coronary heart disease and mortality in subjects $>60$ years old, ${ }^{18}$ while DBP $\leq 60 \mathrm{mmHg}$ was associated with higher CV mortality in patients with systolic hypertension aged $>70$ years. ${ }^{19} \mathrm{Be}-$ cause low DBP impairs coronary blood flow during diastole, it could cause myocardial ischemia and the progression of HF. The present study provided similar results to these findings mentioned here.

In contrast, the OPTIMIZE-HF trial showed that a lower SBP at admission was 1 of the predictors for the combined endpoint of death or re-hospitalization within 60-90 days after discharge. DBP, however, was not included among the candidate variables. ${ }^{20}$ The Canada community-based study indicated that a lower SBP was a predictor of mortality among elderly patients with HF. ${ }^{21}$ The reasons why we found DBP to be a predictor of re-hospitalization in the present analysis are as follows: (1) DBP was not assessed in some other studies; (2) the present patient cohort (aged 67.2 \pm 15.2 years) was younger than the Canada HF patient cohort (aged $75.3 \pm 11.8$ years) and the OPTIMIZE-HF cohort (aged 73.1 \pm 14.2 years); and (3) the mean SBP of the present patients at discharge $(112.2 \pm 16.3 \mathrm{mmHg})$ was lower than that of the Canada HF cohort $(148 \pm 34 \mathrm{mmHg})$ or the OPTIMIZE-HF cohort $(124.3 \pm 24 \mathrm{mmHg})$. The present finding that a low DBP may increase the re-hospitalization rate indicates that DBP can be an important predictor of rehospitalization provided that SBP is not high. Although the reason for the association of DBP with re-hospitalization for $\mathrm{HF}$ still needs to be elucidated, careful BP monitoring is necessary in patients with HF.

We found that BUN, DBP and plasma BNP are important predictors of re-hospitalized HF, and further consideration of what this result means, is needed. First, the prevalence (76.9\%) of DCM in the present study was greater than in the JCARECARD study (24.0\%), suggesting that the degree of HF in the present study was higher than average. Severe HF causes renal dysfunction, which may increase BUN, suggesting that high BUN is linked to the severity of HF and, as suggested by cardio-renal syndrome, the correction of BUN may become a target for HF treatment using ACEI or ARB..$^{22-25}$ In the BEST study, the use of high-dose loop diuretics (total daily dose $\geq 160 \mathrm{mg}$ furosemide equivalents) was associated with significantly increased mortality in patients with BUN $>21.0 \mathrm{mg} / \mathrm{dl} .{ }^{7}$ Patients with a more severe degree of HF generally received larger doses of loop diuretics and were required to evaluate volume management strategies. This is in agreement with the present study (Table 1). In addition, the measurement of plasma BNP has been useful to determine the severity of HF because BNP is secreted in response to ventricular wall stress. ${ }^{26}$ Indeed, $\beta$-blockers are known to affect plasma BNP, and Matsumura et al indicated that low-dose regimens of ACEI/ $\mathrm{ARB}$ or $\beta$-blockers have favorable effects on the prognosis of
Japanese patients with DCM. ${ }^{27}$ The decreasing of plasma BNP would be an excellent strategy in the treatment of HF patients. In contrast, lower DBP may be the result of altered peripheral arterial capacitance or resistance and low cardiac output due to HF. Low DBP can be a surrogate marker of HF severity but does not appear to be an appropriate target or guide for HF treatment.

\section{Study Limitations}

The main limitations of this study were its retrospective design and observational nature. As is the case for all retrospective analyses, it is possible that unrecognized or recognized confounders influenced the results despite adjustment for various factors. Various factors that can alter BUN level, such as medication dosage, cachexia, a high protein diet, and muscle wasting, were not assessed. Thus, prospective studies are needed to establish the predictors of re-hospitalization and CV death such as BUN or DBP. We used serum $\mathrm{Cr}$ as a surrogate marker of renal function. The Cockroft-Gault and Modification of Diet in Renal Disease (MDRD) formulae for eGFR incorporate age and gender to account for differences in muscle mass. Because these factors were included in the present regression model, the predictors might have cancelled each other out, so we used the serum $\mathrm{Cr}$ level as was done in the OPTIME-CHF trial. Also, Smilde et al compared GFR estimated using different formulae with measured GFR in patients with systolic HF and found that all formulae had inaccuracies, ${ }^{28}$ therefore we used serum $\mathrm{Cr}$ instead of eGFR.

\section{Conclusions}

High serum BUN ( $\geq 22.5 \mathrm{mg} / \mathrm{dl})$, high plasma BNP $(\geq 250 \mathrm{pg} / \mathrm{ml})$, and low DBP $(<60 \mathrm{mmHg})$ predict $\mathrm{CV}$ events in patients hospitalized for ADHF. These risk factors may be useful to distinguish low-risk patients from those at high risk who may benefit from closer monitoring and more aggressive treatment.

\section{Disclosures}

Sources of funding: this work was supported by grants-in-aids from the Japanese Ministry of Health, Labor, and Welfare, and the Japanese Ministry of Education, Culture, Sports, Science and Technology, and by Grants from the Japan Heart Foundation, and the Japan Cardiovascular Research Foundation. Conflict of interest: none.

\section{References}

1. Krumholz HM, Parent EM, Tu N, Vaccarino V, Wang Y, Radford MJ, et al. Readmission after hospitalization for congestive heart failure among medicare beneficiaries. Arch Intern Med 1997; 157: 99-104.

2. Goldberg RJ, Ciampa J, Lessard D, Meyer TE, Spencer FA. Longterm survival after heart failure: A contemporary population-based perspective. Arch Intern Med 2007; 167: 490-496.

3. Cuffe MS, Califf RM, Adams KF Jr, Benza R, Bourge RC, Colucci WS, et al. Short-term intravenous milrinone for acute exacerbation of chronic heart failure: A randomized controlled trial. JAMA 2002; 287: $1541-1547$.

4. Binanay C, Califf RM, Hasselblad V, O'Connor CM, Shah MR, Sopko $\mathrm{G}$, et al; ESCAPE Investigators and ESCAPE Study Coordinators. Evaluation study of congestive heart failure and pulmonary artery catheterization effectiveness: The ESCAPE trial. JAMA 2005; 294: $1625-1633$.

5. Shiba N, Nochioka K, Miura M, Kohno H, Shimokawa H; CHART2 Investigators. Trend of westernization of etiology and clinical characteristics of heart failure patients in Japan: First report from the CHART-2 study. Circ J 2011; 75: 823-833.

6. Tsuchihashi-Makaya M, Hamaguchi S, Kinugawa S, Yokota T, Goto $\mathrm{D}$, Yokoshiki H, et al; JCARE-CARD Investigators. Characteristics and outcomes of hospitalized patients with heart failure and reduced vs preserved ejection fraction: Report from the Japanese Cardiac Registry of Heart Failure in Cardiology (JCARE-CARD). Circ J 2009; 73: $1893-1900$. 
7. Testani JM, Cappola TP, Brensinger CM, Shannon RP, Kimmel SE. Interaction between loop diuretic-associated mortality and blood urea nitrogen concentration in chronic heart failure. $\mathrm{J} \mathrm{Am} \mathrm{Coll} \mathrm{Cardiol}$ 2011; 58: $375-382$.

8. Fonarow GC, Adams KF Jr, Abraham WT, Yancy CW, Boscardin WJ, ADHERE Scientific Advisory Committee, Study Group, and Investigators. Risk stratification for in-hospital mortality in acutely decompensated heart failure: Classification and regression tree analysis. JAMA 2005; 293: 572-580.

9. Giamouzis G, Kalogeropoulos AP, Georgiopoulou VV, Agha SA, Rashad MA, Laskar SR, et al. Incremental value of renal function in risk prediction with the Seattle Heart Failure Model. Am Heart J 2009; 157: 299-305.

10. Cauthen CA, Lipinski MJ, Abbate A, Appleton D, Nusca A, Varma A, et al. Relation of blood urea nitrogen to long-term mortality in patients with heart failure. Am J Cardiol 2008; 101: 1643-1647.

11. Sands JM. Mammalian urea transporters. Ann Rev Physiol 2003; 65: 543-566.

12. Cohn JN, Levine TB, Olivari MT, Garberg V, Lura D, Francis GS, et al. Plasma norepinephrine as a guide to prognosis in patients with chronic congestive heart failure. N Engl J Med 1984; 311: 819-823.

13. Cheng V, Kazanagra R, Garcia A, Lenert L, Krishnaswamy P, Gardetto $\mathrm{N}$, et al. A rapid bedside test for B-type peptide predicts treatment outcomes in patients admitted for decompensated heart failure: A pilot study. J Am Coll Cardiol 2001; 37: 386-391.

14. Kociol RD, Horton JR, Fonarow GC, Reyes EM, Shaw LK, O'Connor $\mathrm{CM}$, et al. Admission, discharge, or change in B-Type natriuretic peptide and long-term outcomes: Data from Organized Program to Initiate Lifesaving Treatment in Hospitalized Patients With Heart Failure (OPTIMIZE-HF) linked to Medicare claims. Circ Heart Fail 2011; 4: 628-636.

15. Nishiyama K, Tsutamoto T, Yamaji M, Kawahara C, Fujii M, Yamamoto T, et al. Biological variation of brain natriuretic peptide and cardiac events in stable outpatients with nonischemic chronic heart failure. Circ J 2011; 75: 341-347.

16. Logeart D, Thabut G, Jourdain P, Chavelas C, Beyne P, Beauvais F, et al. Predischarge B-type natriuretic peptide assay for identifying patients at high risk of re-admission after decompensated heart failure. J Am Coll Cardiol 2004; 43: 635-641.

17. Javaheri S, Shukla R, Zeigler H, Wexler L. Central sleep apnea, right ventricular dysfunction, and low diastolic blood pressure are predictors of mortality in systolic heart failure. J Am Coll Cardiol 2007; 20: $2028-2034$.

18. Franklin S, Larson MG, Khan SA, Wong ND, Leip EP, Kannel WB, et al. Does the relation of blood pressure to coronary heart disease risk change with aging? The Framingham Heart Study. Circulation 2001; 103: $1245-1249$.

19. Protogerou AD, Safar ME, Iaria P, Safar H, Le Dudal K, Filipovsky J, et al. Diastolic blood pressure and mortality in the elderly with cardiovascular disease. Hypertension 2007; 50: 172-180.

20. O'Connor CM, Abraham WT, Albert NM, Clare R, Gattis Stough W, Gheorghiade M, et al. Predictors of mortality after discharge in patients hospitalized with heart failure: An analysis from the Organized Program to Initiate Lifesaving Treatment in Hospitalized Patients with Heart Failure (OPTIMIZE-HF). Am Heart J 2008; 156: $662-$ 673.

21. Lee DS, Austin PC, Rouleau JL, Liu PP, Naimark D, Tu JV. Predicting mortality among patients hospitalized for heart failure: Derivation and validation of a clinical model. JAMA 2003; 290: 2581-2587.

22. Maschio G, Alberti D, Janin G, Locatelli F, Mann JF, Motolese M, et al. Effect of the angiotensin-converting enzyme inhibitor benazepril on the progression of chronic renal insufficiency: The Angiotensin-Converting-Enzyme Inhibition in Progressive Renal Insufficiency Study Group. N Engl J Med 1996; 334: 939-945.

23. The SOLVD Investigators. Effect of enalapril on survival in patients with reduced left ventricular ejection fractions and congestive heart failure. N Engl J Med 1991; 325: 293-302.

24. Granger CB, McMurray JJ, Yusuf S, Held P, Michelson EL, Olofsson $\mathrm{B}$, et al; CHARM Investigators and Committees. Effects of candesartan in patients with chronic heart failure and reduced left ventricular systolic function intolerant to angiotensin-converting-enzyme inhibitors: The CHARM-Alternative trial. Lancet 2003; 362: 772-776.

25. Packer M, Coats AJ, Fowler MB, Katus HA, Krum H, Mohacsi P, et al; Carvedilol Prospective Randomized Cumulative Survival Study Group. Effect of carvedilol on survival in severe chronic heart failure. N Engl J Med 2001; 344: 1651-1658.

26. Jourdain P, Jondeau G, Funck F, Gueffet P, Le Helloco A, Donal E, et al. Plasma brain natriuretic peptide-guided therapy to improve outcome in heart failure: The STARS-BNP Multicenter Study. J Am Coll Cardiol 2007; 49: 1733-1739.

27. Matsumura Y, Takata J, Kitaoka H, Kubo T, Baba Y, Hoshikawa E, et al. Long-term prognosis of dilated cardiomyopathy revisited: An improvement in survival over the past 20 years. Circ $J$ 2006; 70: 376-383.

28. Smilde TD, van Veldhuisen DJ, Navis G, Voors AA, Hillege HL. Drawbacks and prognostic value of formulas estimating renal function in patients with chronic heart failure and systolic dysfunction. Circulation 2006; 114: 1572-1580. 